\title{
The Neuroinflammasome in Alzheimer's Disease and Cerebral Stroke
}

\author{
Jong-hoon Lee ${ }^{a}$ Chul Joong Lee ${ }^{b}$ Jungwuk Park ${ }^{c}$ So Jeong Lee ${ }^{d}$ \\ Su-hee Choi $^{\mathrm{e}}$ \\ ${ }^{a}$ Science and Research Center, Seoul National University College of Medicine, Seoul, Republic of Korea; ${ }^{b}$ Zein Pain \\ Clinic Seongbuk, Seoul, Republic of Korea; ' $R$ Research Center of Integrative Functional Medicine, Department of \\ Neurosurgery, Chungdam Hospital, Seoul, Republic of Korea; ${ }^{d}$ Department of BioSciences, Wiess School of Natural

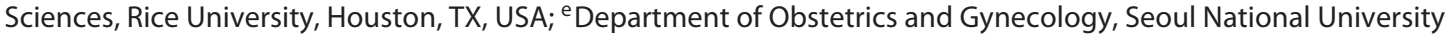 \\ Hospital, Seoul, Republic of Korea
}

\section{Keywords}

Alzheimer's disease $\cdot 4,4^{\prime}$-Diaminodiphenyl sulfone (dapsone) - Lepromatous leprosy (Hansen's disease) . Monoacetyldapsone · Parkinson's disease · NLRP3 .

Myeloperoxidase · Toll-like receptor

\begin{abstract}
Aim/Background: This review investigated a patient with Alzheimer's disease (AD) treated with 4,4'-diaminodiphenyl sulfone (DDS) as a neuroinflammasome competitor. Methods: We monitored AD's progression through numeric clinical staging (NCS) with a new biomarker. NCS was determined by the presence of $A D$ symptoms and neuropsychiatric (NP) symptoms caused by anti-AD (AAD) drugs (D) as a biomarker. We also monitored the function of DDS for stroke in a nointake emergency state. Results: By introducing (D), AD's progression was monitored through NCS staging. AAD side effects and neuropsychiatric symptoms were identified. DDS was stopped in patients with stroke with NCS 6 caused by $A A D$, and it rapidly proceeded to cerebral infarct. Conclusions: $A A D$ can occasionally exacerbate $A D$ and stroke. $D D S$ can alleviate mild cognitive impairment $(\mathrm{MCl})$, early $A D$ and
\end{abstract}

stroke. We clinically confirmed the role of DDS as a neuroinflammasome competitor after stroke. DDS preserved neuronal survival within 24-55 h in the Seoul Study cohort.

(c) 2021 The Author(s)

Published by S. Karger AG, Basel

\section{Introduction}

In an attempt to prevent the progression from mild cognitive impairment (MCI) to Alzheimer's disease (AD), a prospective cohort was created in 2010 based on the prevention and treatment of dementia by administering 4,4'-diaminodiphenylsulfone (DDS) [1], its didextrose sulfonate derivatives, and other closely related sulfones (sulfone and thiazolsulfone) [2,3]. The patient took DDS $100 \mathrm{mg}$ once a day from 2010 to 2015 for the treatment of MCI (online suppl. 7, pp. 1-4; see www. karger.com/doi/10.1159/000516074 for all online suppl. material) [4]. Then, in 2016, the production of DDS ceased in Korea [5]. In June 2018, the patient was then diagnosed with $\mathrm{AD}$ (online suppl. 6, p. 1, p. 29) [4].

Correspondence to:

Jong-hoon Lee, science@ research.re.kr

karger@karger.com www.karger.com/dee

2021 The Author(s)

Published by S. Karger AG, Basel

Karger"

BOPEN ACCESS 
DDS, initially approved for leprosy, has potent antimicrobial effects, even in small doses [6]. This study shows that DDS is also a neuroinflammasome competitor. To demonstrate this, we introduced the application of a new biomarker that can be used to treat and manage AD by applying step-by-step numeric clinical staging (NCS) according to the treatment of neuroinflammation.

\section{Materials and Methods}

The Seoul Study was a prospective cohort study of patients diagnosed with MCI in the period from February 2008 to June 2020. All methods were carried out in accordance with relevant guidelines and regulations.

The Use of Ani-AD Drugs as a New Biomarker of NCS

The raw data for AD were prepared according to "symptombased categorical cognitive impairment stage," i.e., cognitively unimpaired, mild cognitive impairment (MCI), or dementia. This 3-category division serves as the basis for cognitive categorization in many ongoing studies [7]. NCS was recorded according to the 2018 "NIA-AA Research Framework" as 05-02-2008 Stage 3, 27 06-2018 Stage 4, 06-11-2018 Stage 5, and 14-01-2019 Stage 3, based on Korean neuropsychiatric medical records and magnetic resonance imaging (MRI) reports. When recording NCS stage $2 \rightarrow 3 \rightarrow 4 \rightarrow 5 \rightarrow 3$, we used the following biomarkers: $\beta$-amyloid deposition $(\mathrm{A})$, pathologic tau $(\mathrm{T})$, and neurodegeneration $(\mathrm{N})$.

In this study, anti-AD (AAD) drugs, referred to (D) were used as a new biomarker of NCS [8]. In the periods 27-06-2018 to 0110-2018 and 06-11-2018 to 21-11-2018, AAD use caused side effects. We examined patients with the same symptoms [9-12]. After AAD use was stopped from 01-10-2018 to 22-11-2018, the NCS changed from stage 6 to stage 5. After neuroinflammasome treatment, it changed from stage 5 to stage 3 .

We recorded the following NCS values: 05-02-2008 Stage 3, 27 06-2018 Stage 4, 27-06-2018 01-10-2018 Stage 6, 01-10-2018 Stage 5, 06-11-2018 Stage 5, 06-11-2018 16-11-2018, 21-11-2018 Stage 6, 22-11-2018 Stage 5, and 14-01-2019 Stage 3.

Case Report of Cerebral Infarction and a Neuroinflammasome Competitor

This study is based on the results of the Seoul Study cohort. Patients' medical records were issued in accordance with Korean medical law. All medical records in this supplement are copies of patients' medical charts.

DDS blocks the bacterial synthesis of dihydrofolic acid via competition with $p$-aminobenzoic acid for dihydropteroate synthetase's active site [13]. In addition to its antimicrobial effects, DDS is a potent anti-inflammatory agent with high efficacy in dermatitis herpetiformis and a wide variety of other inflammatory dermatological conditions [6]. DDS, that inhibits inflammation without compromising the adaptive immune response, could be the most effective therapeutic strategy. DDS, as an inflammasome competitor [14] should be effective against neuroinflammasomes.

We analyzed the Seoul Study cohort of elderly patients with MCI who underwent precise MRI examinations for stroke in May 2020. The DH Hospital conducted medical examinations (online suppl. 1, 1-1 [11-05-2020-diffusion MRI- Rx image], online suppl. 1-2 [12-05-2020-diffusion MRI- Rx image], online suppl. 1-3 [12-05-2020-perfusion MRI- Rx image]), CT (online suppl. 1, p. 15, p. 18, p. 19], online suppl. 1-4 [11-05-2020-CT- Rx image], online suppl. 1-5 [13-05-2020-CT- Rx image]), chest AP (online suppl. 1, p. 13, p. 20], online suppl. 1-6 [11-05, 20-05-2020-chestRx image], and medical report (online suppl. 1, pp. 4-12).

We hypothesized that the deterioration of ischemic stroke to cerebral infarct could be prevented by NLRP3 inflammasome inhibitors [15], such as DDS. The DDS tablets were produced by the local pharmaceutical company, but production was stopped and since then, the Korea FDA has designated DDS as an antiretraction drug and produces it only for leprosy/Hansen's disease (HD) sufferers. The Korea Orphan and Essential Drug Center imported it from Germany. After administering the 2 types of DDS to patients, we found a large difference in clinical effectiveness. DDS from the local pharmaceutical company had one-third the effective dose $\left(\mathrm{ED}_{50}\right)$ of the DDS from Germany.

On 10 May 2020, the patient was dosed twice daily with $200 \mathrm{mg}$ (2 times daily) and close monitoring revealed the following; rash/ exanthema/erythema/erythroderma/mucosal involvement leukocytosis/eosinophilia [16], the appearance of a mononucleosis infection/acute renal failure/hepatitis/liver toxicity [17], hemolytic anemia/methemoglobinemia [18], cholangitis/colitis/thyroiditis/ myocarditis/dapsone-induced hypersensitivity syndrome-associated complete atrioventricular block/pneumonitis [19], pancreatitis/pleural effusion [20], and myocardial injury/pneumonia/multiple organ failure [21].

\section{Corroboration of the Neuroinflammasome Findings of the}

Seoul Study

In Korea, during the SARS-CoV-2 epidemic, children were prohibited from visiting their parents in nursing hospitals [22]. It became difficult for carers to interact with older adults at close range. In nursing hospitals, chemical restraint increased substantially to reduce hospital labor costs during the same period [23].

Medical staff found the patient to suffer from endocarditis and pulmonary effusion symptoms (online suppl. 2, 2-1). The patient took DDS at lunch (12:00) on 12 September 2020, was transferred to Inje University Seoul Paik Hospital, and stopped taking DDS until 19:00 on 15 September 2020. Only after the patient's guardian submitted a memorandum of responsibility (online suppl. 2, p. 6 and 2-2, p. 25) was the patient able to retake DDS with the permission of Professor Jong-Chun Nah, a cardiology specialist at the hospital. The patient's cognitive state over the course of $55 \mathrm{~h}$ was observed through medical records (online suppl. 2, 2-2).

\section{Results}

\section{AAD Drugs as a New Biomarker of NCS}

Observational studies of $\mathrm{AD}$ after the treatment of neuroinflammation:

(1) Syndromal staging of the cognitive continuum (SSC) 
Table 1. Treatment of neuroinflammation with (D) (added NCS information is italicized)

\begin{tabular}{|c|c|c|c|c|c|}
\hline Year & NCS [7] & Online supplement [4] & SSC & $\begin{array}{l}\text { NIA- } \\
\text { AA }\end{array}$ & $\begin{array}{l}\text { NIA-AA + } \\
\text { (D) }\end{array}$ \\
\hline 2007 & Stage 2 & $\begin{array}{l}\text { Online supplement_6.pdf (p. 2; online suppl. } 6 \text { [4]) } \\
\text { The patient visited in December } 2007 \text { with recent memory disturbance } \\
\text { There were no abnormalities in the findings }\end{array}$ & $\begin{array}{l}\text { Cognitively } \\
\text { unimpaired }\end{array}$ & Stage 2 & Stage 2 \\
\hline 05-02-2008 & Stage 3 & $\begin{array}{l}\text { Online supplement_4.pdf (p. } 1 \text {; online suppl. } 4[4] \text { ) } \\
\text { MMSE = 23, CERAD }=45, \text { CDR }=0.5 / 0.5 / 1.5, \text { MRI; hippocampal atrophy } \\
\text { Assessment: MCI, amnestic } \\
\text { Plan: observation }\end{array}$ & MCI & Stage 3 & Stage 3 \\
\hline
\end{tabular}

Seoul Study - Trial of DDS for AD prevention

DDS supply was suspended in Korea from 2016

27-06-2018 Stage 4 Online supplement_6.pdf (p. 1, p. 2; online suppl. 6 [4])

On 20 June 2018, the patient presented with leg pain and memory impairment

Dementia Stage 4 Stage 4

The patient scored 22/30 on the MMSE and 4 on the GDS 4, with decreases in

time-keeping, memory and calculation ability

On 27 June 2018, brain MRI imaging showed multiple lacunar infarction and

cerebral

cortical atrophy

27-06-2018 Stage $6 \quad$ Side effects of $(D)$ prescribed by the doctor

Stage 6

01-10-2018

Abdominal pain, bradycardia, heart failure, angina pectoris, perineal incontinence,

dysphagia, anemia, weight loss, peripheral edema, edema, leg cramps, myalgia,

irritability,

anxiety progression, convulsions, transient mental disorder, gait abnormality, apathy,

dizziness, delusions, increased frequency of dreaming, increased ecstatic mood, pyramidal symptoms, seizures/hypertension, exercise reduction, difficulty

breathing, dysuria

\begin{tabular}{|c|c|c|c|c|c|}
\hline $10-2018 \sim$ & Stage 5 & Stop $A A D$ & & & \\
\hline 06-11-2018 & Stage 5 & $\begin{array}{l}\text { Online supplement_1.pdf (pages 1-2; online suppl. } 1 \text { [4]) } \\
\text { MMSE 18/30, CDR 1.0, FAB 16/18, NPI-Q 30, K-IADL 0.6, GDS 3, GSS 0, Lewy } \\
\text { bodies } 0\end{array}$ & Dementia & Stage 5 & Stage 5 \\
\hline
\end{tabular}

06-11-2018 Stage 6 Side effects of $(D)$ online supplement_2.pdf (p. 1; online suppl. 2 [4])

Stage 6

21-11-2018

Abdominal pain, bradycardia, heart failure, angina pectoris, perineal incontinence,

dysphagia, anaemia, weight loss, peripheral edema, edema, leg cramps, myalgia,

irritability,

anxiety progression, convulsions, transient mental disorder, gait abnormality, apathy,

dizziness, delusions, increased frequency of dreaming, increased ecstatic mood, pyramidal symptoms, seizures/ hypertension, exercise reduction, difficulty breathing, dysuria

22-11-2018 Stage 5 Stop AAD Stage 5

The Korea Orphan and Essential Drug Center imported and supplied DDS

28-11-2018 DDS, online supplement_3.pdf (p. 1; online suppl. 3 [4])

The Korea Orphan and Essential Drug Center imported and supplied DDS on

2018-11-28,

2018-12-27, and 2019-04-02

\begin{tabular}{ll}
\hline 14-01-2019 Stage 3 & Online supplement_1.pdf (pp. 3-5; online suppl. 1 [4]) \\
& $\begin{array}{l}\text { MMSE 17/30, CDR 1.0, FAB 14/18, NPI-Q 0, K-IADL 0.3, GDS 2, GSS 2, Lewy } \\
\text { bodies 0 }\end{array}$
\end{tabular}

01-05-2020 Stage 3 DDS supply resumed in Korea in January 2020. The Seoul Study cohort was $\quad$ MCI Stage 3 prescribed

150-300 mg DDS as a competitor for the inflammasome

The Neuroinflammasome in $\mathrm{AD}$ and Cerebral Stroke 


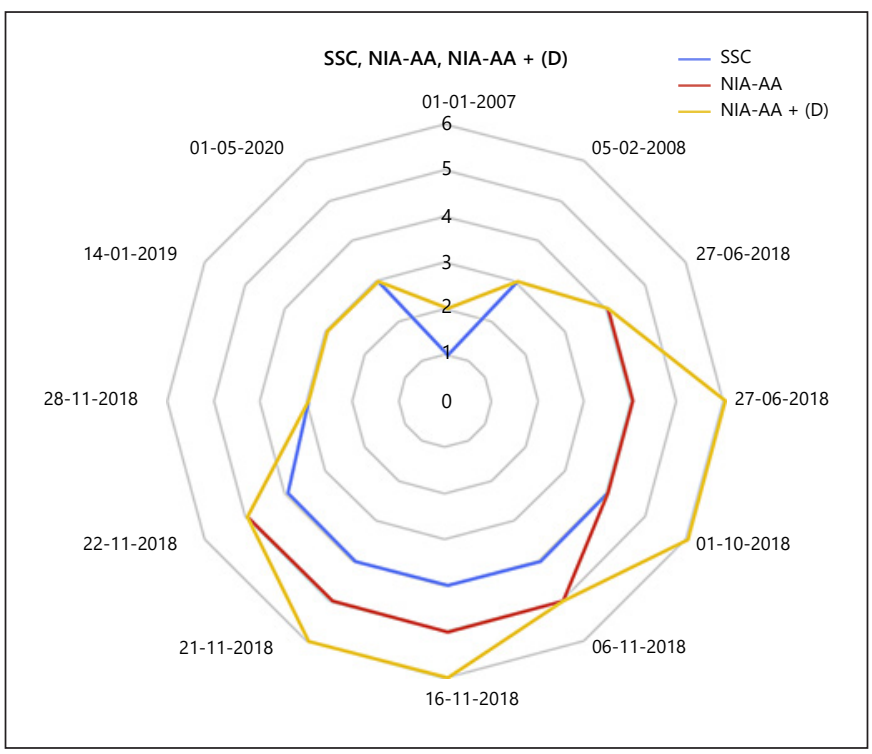

Fig. 1. The ranges of syndromal staging of the cognitive continuum (SSC), the National Institute on Aging (NIA) at National Institutes of Health and the Alzheimer's Association published revised guidelines (NIA-AA) for modernization of the diagnosis of Alzheimer's disease, and NIA-AA + (D) are plotted as a radial chart. NIA-AA standard schematically represents SSC. SSC has the smallest range compared to the NIA-AA and NIA-AA + (D). NIA$\mathrm{AA}+(\mathrm{D})$ monitors a wider range than the NIA-AA. The management scope for Alzheimer's disease will be further expanded if the NIA-AA standard includes (D).

December 2007 "cognitively unimpaired" $\rightarrow$ 05-012008 "MCI" 27-06-2018 "dementia" $\rightarrow$ 11-06-2018 “dementia" $\rightarrow$ 14-01-2019 "MCI."

(2) NCS 2007 stage $2 \rightarrow 05-02-2008$ stage $3 \rightarrow 27-06$ 2018 stage $4 \rightarrow 06-11-2018$ stage $5 \rightarrow 14-01-2019$ stage 3 .

(3) NIA-AA (A) (T) (N)) + new biomarker (D)

NCS 2007 Stage $2 \rightarrow$ 05-02-2008 stage $3 \rightarrow$ 27-06-2018 stage $4 \rightarrow$ 27-06-2018 01-10-2018 stage $6 \rightarrow 01-10-2018$ stage $5 \rightarrow$ 06-05-2018 stage $5 \rightarrow$ 06-11-2018 16-11-2018 stage $6 \rightarrow 22-11-2018$ stage $5 \rightarrow 14-01-2019$ stage 3 .

The comparison table of the above study results can be seen in Table 1.

AD Cases 1-5 of the Seoul Study followed a similar path. There were 2 stage 6 cases concealed by the appearance of stage 4 or 5 , which could not be monitored (Fig. 1).

\section{Cerebral Infarction and DDS as a}

Neuroinflammasome Competitor in the Seoul Study

The attending physician stopped the brain-cell protective drug (DDS) that the patient had been taking in a stable state after stroke onset on 10 May. He prescribed as- pirin for antithrombotic treatment and acetylcholine precursor. The patient's NCS was stage 6 after $5 \mathrm{~h}$ according to the increase of acetylcholine (online suppl. 1, p. 8 [22:44, 01:00]).

The patient did not take DDS on 11 and 12 May 2020. After antithrombotic treatment, the patient's muscle power changed from grade $1(+)$ to $(4+)$ at $08: 00$. However, it suddenly changed from $(4+)$ to $(1+)$ at $11: 30$ on 12 May 2020. On MRI, the patient's left cerebral infarct was further enlarged (online suppl. 1, p. 16, p. 17; 1-2, 1-3). After $72 \mathrm{~h}$, the patient took DDS again (online suppl. 1, p. 12 [08:50]). The patient's condition did not worsen despite having pneumonia, cardiomegaly, and suspected pulmonary hypertension (online suppl. 1, p. 19).

Although traditional cardiovascular risk factors account for the majority of strokes, infectious pathogens may pose an additional risk and, in some cases, play a direct causal role. Systemic infections have been associated with an increased risk of strokes, and inflammation stimulation has been thought to be the predominant mechanism of certain pathogens [24]. The cerebral stroke in this case was caused by pneumonia (online suppl. 1, p. 19, p. 20; online suppl. 1-5 [13-05-2020- CT- Rx image], 2-6 [11-05-2020, 20-05-2020-Chest- Rx image]) S. pneumoniae and $H$. influenzae were found in the culture test (online suppl. 1, p. 21).

\section{Neuroinflammasome Causes Exacerbation and DDS Weakens It Again}

After the patient was discharged on 20-05-2020, medical staff stopped the acetylcholine precursor in the rehabilitation hospital and the patient recovered to NCS stage 3 .

Medical staff found the patient suffering from endocarditis and pulmonary effusion symptoms again (online suppl. 2, 2-1). From lunch (12:00) on 12 September to 19:00 on 15 September 2020, the patient's progress during and after $55 \mathrm{~h}$ of DDS discontinuation was monitored. DDS was loaded at 19:00 on 15 September 2020. Below are the data from the patient's medical record from 28 September to 9 December 2020 (online suppl. 2, p. 1, p. 2).

After administering DDS at 19:00 on 15 September and at $18: 53$ on 16 September 2020, the patient became drowsy from stupor. The patient's cognitive condition is shown in Table 2.

Except for taking DDS, the patient's treatment did not change, but there was a clear change in consciousness, and infective endocarditis improved to a stable state. 


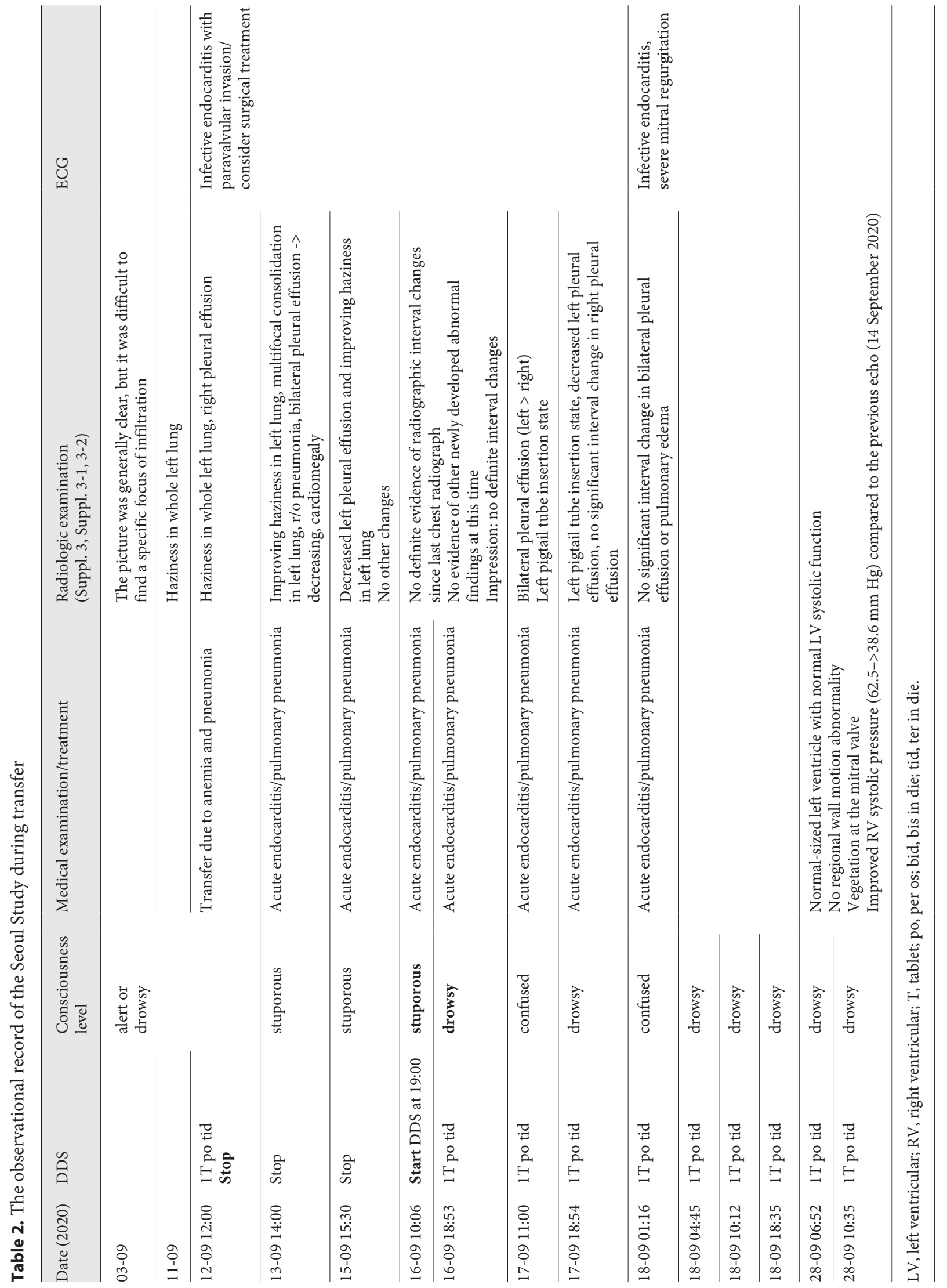


The NLRP3 neuroinflammasome is a common cause of cognitive impairment in $\mathrm{AD}$, stroke, and inflammation by certain pathogens. The action of DDS demonstrates that the inhibition (control) of NLRP3 is a new target for therapeutics.

\section{Discussion}

\section{The Alzheimer's Continuum}

For clinical research, the Alzheimer's continuum (A + $\mathrm{T}+[\mathrm{N}]+[\mathrm{D}])$ was selected based on biomarkers. Before AD progressed, biomarkers were changed. Therefore, clinical symptoms and biomarkers were separated from $\mathrm{AD}$ diagnosis, and $\mathrm{AD}$ was defined only by changes in biomarkers [7]. The AD criteria biologically classify cognitive impairments separately as symptoms/signs caused by these diseases. AD problems may include the following: depression, apathy, social withdrawal, mood swings, distrust in others, irritability and aggressiveness, changes in sleeping habits, wandering, loss of inhibitions, and delusions such as believing something has been stolen [25]. As of mid-2019, several AD drugs were available worldwide: donepezil, galantamine, rivastigmine and memantine [26]. Aripiprazole, olanzapine, risperidone, quetiapine, haloperidol, selective serotonin-reuptake inhibitors, and carbamazepine are used to control the psychiatric symptoms associated with dementia [27-32]. However, it was challenging to differentiate whether AAD caused symptoms because of the Korea Dementia Act and the health insurance system. (D) can be used as a biomarker to distinguish the symptoms caused by AAD. Since the side effects of $\mathrm{AAD}$ have been reported [33,34], it is necessary to record the biomarker (D).

The FDA warned that dementia-related antipsychotic drugs increase mortality. The boxed warning reads as follows: "Elderly patients with dementia-related psychosis treated with antipsychotic drugs are at an increased risk of death" [33]. More recent studies from many countries confirm that antipsychotic drugs should not be prescribed for dementia patients, as they significantly increase the risk of seizures and all-cause mortality [34]. Therefore, to distinguish the symptoms caused by AAD or $\mathrm{AD}$, it is necessary to stop taking $\mathrm{AAD}$ and observe a patient's clinical progress. In this study, when acetylcholine precursor was administered to the patient, the patient's state changed from the NCS 6 stage. Medical staff must label the $\mathrm{AAD}$ as a biomarker (D) and monitor the patient's condition for changes.
$D D S$ to Prevent $A D$ and Amyloid-beta Neurotoxicity

At first review [35], DDS was deemed a therapeutic, preventative agent in $\mathrm{AD}$, according to reports [36-38]. However, in the second review [39], DDS was not a therapeutic, preventative agent in $\mathrm{AD}[38,40]$. There were different interpretations of the commonly cited "decreased $A \beta$ and increased abnormal tau deposition in the brain of aged patients with leprosy." It has been reported that amyloid-beta $(A \beta)$ protein deposits were significantly lower in the temporal cortex and hippocampal formation of elderly HD patients and that patients with T-type leprosy (who did not take DDS) exhibited slightly more $A \beta$ deposition than those with L-type leprosy. The brains of HD patients show high abnormal tau deposition in the neurons and neural threads despite the low levels of $A \beta$ deposition [38]. Mycobacterium leprae, which induces leprosy, was assumed to cause the low incidence of $\mathrm{AD}$ in HD [41]. However, the next researchers claimed a null hypothesis because the $A \beta$ removal function of DDS and the dementia reduction by $M$. leprae are irrelevant [1].

The inflammasome competitor model of DDS shows a reaction pattern that is a typical molecular model of electronic clouds. Therefore, in vitro or in vivo, it can show pathological findings that can be either this or that. The autopsy findings of leprosy's brain pathology at the sanatorium in Japan are variable. The pathologic findings in the previous review are consistent with those of a typical inflammasome competitor. The alternative way science can help us prevent or treat AD is to use an inflammasome competitor and reduce the $\mathrm{AD}$ prevalence rate.

The molecular properties of DDS, including electron density and its Laplacian delocalization index, have been elucidated to shed light on the chemical bonding and atomic and molecular details $[42,43]$. The redox properties of DDS are dependent on amine and sulfone moieties and can explain the oxidation mechanism of DDS by electron transfer. The aniline ring is the nucleophilic moiety conferring potential biological properties via a redox mechanism, mainly electron transfer or oxidation for DDS-NHOH formation [44]. We can understand the various neuropathological findings associated with $\mathrm{HD}$, including unexplained sensory manifestations [45].

DDS should regulate NLRP3 inflammasome activators and a common signaling pathway of SARS-CoV-2 inflammasome activators in the medulla oblongata [46]. It acts via the same competitive therapeutic mechanism to counter the progression of MCI to AD. Korean HD patients on Sorokdo (an island specifically for HD patients) continue to take DDS throughout their lives. This drug appears to have a preventative effect against $\mathrm{AD}$, ac- 
cording to the study of HD patients who have lived there all their lives [47].

\section{Neuroimmunity and Neuroprotection for Stroke Patients}

Hypertension causes blood-brain barrier breakdown via mechanisms involving inflammation, oxidative stress, and circulating vasoactive molecules. It exposes neurons to cytotoxic molecules, leading to neuronal loss, cognitive decline, and impaired recovery from ischemia [48]. Active treatment for elevated blood pressure can decrease perfusion at the cerebral infarction area, thus extending this area [49]. However, there is no evidence that high blood pressure that develops after a stroke indicates stroke severity or is intended to provide collateral blood flow to maintain blood flow to the ischemia area (penumbra) [49-51]. Instead, in 2004, there was a report that patients with stroke had a high mortality rate when hospitalized with high or low blood pressure [51]. There are only reviews reporting that starting treatment for severe hypertension within a few hours of stroke onset can cause a decrease in cerebral blood flow and may be problematic [52]. There is no medical evidence that neglecting high blood pressure can increase a patient's survival rate. However, it has been reported that the stress of being admitted to hospital is actually the main factor causing high blood pressure in stroke patients [50].

Markedly low red-blood cell (RBC) cholesterol and markedly high RBC lipoperoxides may pathologically aggravate cerebral hemorrhage patients and lead to oxidative and lipoperoxidation damage [53]. These factors are positively correlated with erythrocyte deformability [54]. Considering that there are disturbances in the function of erythrocyte membranes and free radicals in acute cerebral infarction, erythrocyte deformity and membrane $\mathrm{Na}+\mathrm{K}+-\mathrm{ATPase}$ activity in acute cerebral infarction patients were lower than those in healthy individuals [55, 56]. Antioxidants such as DDS attenuate microvascular changes in the early phase of experimental pneumococcal meningitis [57]. DDS increases the viability of brain cells in acute stroke. Clinical trials were already conducted in 2013 and the statistics were significant [58]. In 2014, an analysis was published that was very effective and economical in treating acute ischemic stroke patients [59]. In 2016, MRI results were published to compensate for functional loss after brain-cell damage [60]. Also, studies have been reported of protection of brain cells and increased viability in various experiments [61]. The paper claiming that DDS increased the concentration of Parkin in old rats was from a study that was precisely consistent with the patient (online suppl. 7, pp. 1-4; C.-S. Koh, pers. observ.[4]) in the Seoul Study cohort whose Parkinson's symptoms improved [62].

Astrocytes play a crucial role in regulating homeostasis within the central nervous system. Furthermore, they mediate hypoxia-induced changes in pathological conditions associated with the immune response and manipulate mitochondrial function and metabolism. An in vitro study on the transcriptomic profile of astrocytes showed a detailed characterization of hypoxia-induced changes. Analysis of the significant differentially expressed transcripts identified an increase in immune response pathways and dysregulation of the signaling pathways and metabolism, including glycolysis [63]. After administering DDS at 19:00 on 15 September and at 18:53 on 16 September 2020, the patient recovered consciousness. Except for taking DDS, the patient's treatment did not change, but he improved to a stable state of infective endocarditis. DDS also reduced doxorubicin's cardiac toxicity due to its production of free radicals and inflammatory cytokines [64].

DDS has already been used as a substitute for colchicine. The specific targeting of NLRP3 itself or up-/downstream factors of the NLRP3 inflammasome by DDS may be responsible for its observed MCI-preventative effects [1], functioning as a competitor for the SARS-CoV-2 inflammasome [14].

\section{Conclusions}

DDS is a neuroinflammasome competitor. By prescribing this drug for neuroinflammation and brain survival, the incidence of $\mathrm{AD}$ can be reduced by more than two-thirds [1-3]. Early-onset AD and stroke can be treated with DDS in the same manner as MCI when (A), (T), $(\mathrm{N})$, and (D) are recorded as biomarkers. Trials need to be carried out from middle age ( $>40$ years) in parallel, not sequentially, using adaptive trial designs optimized for speed and tested in different populations so that we can ultimately protect everyone.

\section{Acknowledgement}

Soon Joe (09-12-1931 03-01-2021) contributed to making treatment method for MCI and AD, SARS-CoV-2 ARDS. ChangSoon Koh (20-04-1932 06-08-2012) participated as a cofounding researcher. He was the physician to the President of South Korea. He took DDS from 27-12-2010 to 06-07-2011 and reported that DDS could also be used to manage Parkinson's disease. 


\section{Statement of Ethics}

The Science and Research Center, Seoul National University of College of Medicine, Seoul, approved this study, based on FDA guidelines in accordance with the World Medical Association Declaration of Helsinki. The subjects (or their parents or guardians) provided written informed consent. We administered medicines in compliance with medical and pharmacy laws with the informed consent of the patient.

\section{Conflict of Interest Statement}

The authors have no conflicts of interest to declare.

\section{Funding Sources}

There are no funding sources to declare.

\section{Author Contributions}

J.L. designed and performed this study and wrote the manuscript. C.J.L., J.P., and S.C. analyzed the symptoms of intractable $\mathrm{AD}$ and the use of the AAD (D). S.J.L. examined the cerebral infarct patients and wrote online supplements 1,2 .

\section{References}

1 Lee JH, Choi SH, Lee CJ, Oh SS. Recovery of Dementia Syndrome following Treatment of Brain Inflammation. Dement Geriatr Cogn Disord Extra. 2020 Jan;10(1):1-12.

2 McGeer PL, Harada N, Kimura H, McGeer EG, Schulzer M. Prevalence of dementia amongst elderly Japanese with leprosy: apparent effect of chronic drug therapy. Dement Geriatr Cogn Disord. 1992;3(3):146-9.

3 McGeer PL, Harada N, Kimura H, McGeer EG, Schulzer M. Dapsone and promin for the treatment of dementia. Google Patents; 1996.

4 Lee J, Choi S, Lee CJ, Oh S. Supplementary Material for: Recovery of Dementia Syndrome following Treatment of Brain Inflammation 2020.

5 Committee PT. Pharmacy Newsletter of Drug Information. Pharmacy Newsletter. Department of Pharmacy: Seoul National University Hospital; 2016.09. p. 3.

6 Zhu YI, Stiller MJ. Dapsone and sulfones in dermatology: overview and update. $\mathrm{J}$ Am Acad Dermatol. 2001 Sep;45(3):420-34

7 Jack CR Jr, Bennett DA, Blennow K, Carrillo MC, Dunn B, Haeberlein SB, et al.; Contributors. NIA-AA Research Framework: toward a biological definition of Alzheimer's disease. Alzheimers Dement. 2018 Apr;14(4):535-62.

8 Jang JW, Kim S. A New Biological Definition of Alzheimer's Disease: Introduction of 2018 National Institute on Aging-Alzheimer's Association Research Framework. J Korean Neurol Assoc. 2019;37(1):1-7.

9 Dunn NR, Pearce GL, Shakir SA. Adverse effects associated with the use of donepezil in general practice in England. J Psychopharmacol. 2000;14(4):406-8.

10 Birks J, Flicker L. Donepezil for mild cognitive impairment. Cochrane Database Syst Rev. 2006 Jul;(3):CD006104.

11 McLaren AT, Allen J, Murray A, Ballard CG, Kenny RA. Cardiovascular effects of donepezil in patients with dementia. Dement Geriatr Cogn Disord. 2003;15(4):183-8.
12 Sato K, Urbano R, Yu C, Yamasaki F, Sato T, Jordan J, et al. The effect of donepezil treatment on cardiovascular mortality. Clin Pharmacol Ther. 2010 Sep;88(3):335-8.

13 Coleman MD. Dapsone: modes of action, toxicity and possible strategies for increasing patient tolerance. $\mathrm{Br}$ J Dermatol. 1993 Nov;129(5):507-13.

14 Lee JH, An HK, Sohn MG, Kivela P, Oh S. 4,4'-Diaminodiphenyl Sulfone (DDS) as an Inflammasome Competitor. Int J Mol Sci. 2020 Aug;21(17):5953.

15 Ismael S, Zhao L, Nasoohi S, Ishrat T. Inhibition of the NLRP3-inflammasome as a potential approach for neuroprotection after stroke. Sci Rep. 2018 Apr;8(1):5971

16 Lorenz M, Wozel G, Schmitt J. Hypersensitivity reactions to dapsone: a systematic review. Acta Derm Venereol. 2012 Mar;92(2):194-9.

17 Alves-Rodrigues EN, Ribeiro LC, Silva MD, Takiuchi A, Fontes CJ. Dapsone syndrome with acute renal failure during leprosy treatment: case report. Braz J Infect Dis. 2005 Feb;9(1):84-6.

18 Wozel VE. Innovative use of dapsone. Dermatol Clin. 2010 Jul;28(3):599-610.

19 Zhu KJ, He FT, Jin N, Lou JX, Cheng H. Complete atrioventricular block associated with dapsone therapy: a rare complication of dapsone-induced hypersensitivity syndrome. J Clin Pharm Ther. 2009 Aug;34(4):489-92.

20 Ghishan FK. The sulfone syndrome complicated by pancreatitis and pleural effusion in an adolescent receiving dapsone for treatment of acne vulgaris. J Pediatr Gastroenterol Nutr. 1998 Jan;26(1):103-5.

21 Kang KS, Kim HI, Kim OH, Cha KC, Kim H, Lee $\mathrm{KH}$, et al. Clinical outcomes of adverse cardiovascular events in patients with acute dapsone poisoning. Clin Exp Emerg Med. 2016 Mar;3(1):41-5.

22 Coronavirus infection-19 Infection prevention and management in medical institutions (For nursing hospitals), (2020-04).
23 Hong H. [Current affairs planning window] Corona 19 nursing hospital'unmonitored drugs'. KBS NEWS. 2020.09.12.

24 Fugate JE, Lyons JL, Thakur KT, Smith BR, Hedley-Whyte ET, Mateen FJ. Infectious causes of stroke. Lancet Infect Dis. 2014 Sep;14(9):869-80.

25 Daroff RB, Jankovic J, Mazziotta JC, Pomeroy SL. Bradley's neurology in clinical practice ebook: Elsevier Health Sciences; 2015.

26 Hara Y, Kawabe H, editors. Donepezil (Aricept). Drug Discovery in Japan. New York Springer; 2019. pp. 183-205.

27 Bains J, Birks J, Dening T. Antidepressants for treating depression in dementia. Cochrane Database Syst Rev. 2002 Oct;(4):CD003944.

28 Katz IR, Jeste DV, Mintzer JE, Clyde C, Napolitano J, Brecher M; Risperidone Study Group. Comparison of risperidone and placebo for psychosis and behavioral disturbances associated with dementia: a randomized, double-blind trial. J Clin Psychiatry. 1999 Feb;60(2):107-15.

29 Pinheiro D. [Anticonvulsant mood stabilizers in the treatment of behavioral and psychological symptoms of dementia (BPSD)]. Encephale. 2008 Sep;34(4):409-15.

30 Azermai M. Dealing with behavioral and psychological symptoms of dementia: a general overview. Psychol Res Behav Manag. 2015 Jul;8:181-5.

31 Wang F, Feng TY, Yang S, Preter M, Zhou JN, Wang XP. Drug Therapy for Behavioral and Psychological Symptoms of Dementia. Curr Neuropharmacol. 2016;14(4):307-13.

32 Youn H, Jeong HG. Pharmacotherapy for dementia.JKorean Med Assoc. 2018;61(12):75864.

33 Stone M. Mortality and antipsychotic drug use in dementia-related behavioral disorders. US Department of Health and Human Services. Food and Drug Administration, Center for Drug Evaluation and Research; 2005. 
34 Ralph SJ, Espinet AJ. Increased All-Cause Mortality by Antipsychotic Drugs: Updated Review and Meta-Analysis in Dementia and General Mental Health Care. J Alzheimers Dis Rep. 2018 Feb;2(1):1-26.

35 Appleby BS, Cummings JL. Discovering new treatments for Alzheimer's disease by repurposing approved medications. Curr Top Med Chem. 2013;13(18):2306-27.

36 Namba Y, Kawatsu K, Izumi S, Ueki A, Ikeda K. Neurofibrillary tangles and senile plaques in brain of elderly leprosy patients. Lancet. 1992 Oct;340(8825):978.

37 Kimura T, Goto M. Existence of senile plaques in the brains of elderly leprosy patients. Lancet. 1993 Nov;342(8883):1364.

38 Chui DH, Tabira T, Izumi S, Koya G, Ogata J. Decreased beta-amyloid and increased abnormal Tau deposition in the brain of aged patients with leprosy. Am J Pathol. 1994 Oct;145(4):771-5.

39 Appleby BS, Nacopoulos D, Milano N, Zhong $\mathrm{K}$, Cummings JL. A review: treatment of Alzheimer's disease discovered in repurposed agents. Dement Geriatr Cogn Disord. 2013;35(1-2):1-22.

40 Goto M, Kimura T, Hagio S, Ueda K, Kitajima $\mathrm{S}$, Tokunaga $\mathrm{H}$, et al. Neuropathological analysis of dementia in a Japanese leprosarium. Dementia. 1995 May-Jun;6(3):157-61.

41 Endoh M, Kunishita T, Tabira T. No effect of anti-leprosy drugs in the prevention of Alzheimer's disease and beta-amyloid neurotoxicity. J Neurol Sci. 1999 May;165(1):28-30.

42 Rajendran ND, Mookan N, Samuel I, Mookan SB, Munusamy G, Gurudeeban S, et al. A theoretical study of chemical bonding and topological and electrostatic properties of the antileprosy drug dapsone. J Mol Model. 2020 May;26(6):138.

43 Kim SK, Lee SB, Kang TJ, Chae GT. Detection of gene mutations related with drug resistance in Mycobacterium leprae from leprosy patients using Touch-Down (TD) PCR. FEMS Immunol Med Microbiol. 2003 May;36(12):27-32.

44 Mendes AP, Schalcher TR, Barros TG, Almeida ED, Maia CS, Barros CA, et al. A Geometric and Electronic Study of Dapsone. J Comput Theor Nanosci. 2011;8(8):1428-31.
45 Schrödinger E, editor. What Is life? With Mind and Matter and Autobiographical Sketches. New York: Cambridge University Press; 1992.

46 Lee Jh, Kanwar B, Balentine J, Lee CJ, Khattak A, Sergi C. The Method and Results of a Treatment Targeting SARS-CoV-2-Activated Inflammasomes. Research Square. (Under Review).

47 Jong-hoon L, Chul Joong L, Jungwuk P, So Jeong L, Su-Hee C, Sang-Suk O. The Preventive and Treatment of the Neuro-Inflammasome in Sorokdo National Hospital [under review]. Sci Rep. 2021

48 Pires PW, Dams Ramos CM, Matin N, Dorrance AM. The effects of hypertension on the cerebral circulation. Am J Physiol Heart Circ Physiol. 2013 Jun;304(12):H1598-614.

49 Powers WJ. Acute hypertension after stroke. The scientific basis for treatment decisions. Neurology. 1993;43(3 Part 1):461.

50 Carlberg B, Asplund K, Hägg E. Factors influencing admission blood pressure levels in patients with acute stroke. Stroke. 1991 Apr;22(4):527-30.

51 Vemmos KN, Tsivgoulis G, Spengos K, Zakopoulos N, Synetos A, Manios E, et al. Ushaped relationship between mortality and admission blood pressure in patients with acute stroke. J Intern Med. 2004 Feb;255(2):257-65

52 Brott T, Bogousslavsky J. Treatment of acute ischemic stroke. N Engl J Med. 2000 Sep;343(10):710-22.

53 Chen HH, Zhou JF. Low cholesterol in erythrocyte membranes and high lipoperoxides in erythrocytes are the potential risk factors for cerebral hemorrhagic stroke in human. Biomed Environ Sci. 2001 Sep;14(3):189-98.

54 Yuhua YS, Xiaoxian Z. Erythrocyte Membrane ATPases Activities in Hypercholesterolemia Patients [J]Progress In Biochemistry and Biophysics; 1992. p. 1.

55 Jingli Y, Guoxing Z, Zhen Q. The change of erythrocyte membrane ATPase and the injury of free radical in acute cerebral infarction. J Apoplexy Nervous Dis. 1996;(3):5.
$56 \mathrm{Xu}$ Z, Xin P, Jin L. Effect of intravascular He$\mathrm{Ne}$ laser irradiation on blood for erythrocyte deformity and erythrocyte membrane $\mathrm{Na}+$ $\mathrm{K}+$ ATPase in acute cerebral infarction patients. Chin J Phys Ther. 1999(3):03.

57 Pfister HW, Koedel U, Lorenzl S, Tomasz A. Antioxidants attenuate microvascular changes in the early phase of experimental pneumococcal meningitis in rats. Stroke. 1992 Dec;23(12):1798-804.

58 Nader-Kawachi J, Góngora-Rivera F, SantosZambrano J, Calzada P, Ríos C. Neuroprotective effect of dapsone in patients with acute ischemic stroke: a pilot study. Neurol Res. 2007 Apr;29(3):331-4.

59 Cruz-Cruz C, Kravzov-Jinich J, MartínezNúñez JM, Ríos-Castañeda C, Perez ME, Altagracia-Martínez M. Cost-utility analysis in acute ischemic stroke survivors treated with dapsone in a public hospital in Mexico City. J Pharm Health Serv Res. 2014;5(2):95-102.

60 Diaz-Ruiz A, Roldan-Valadez E, Ortiz-Plata A, Mondragón-Lozano R, Heras-Romero Y, Mendez-Armenta M, et al. Dapsone improves functional deficit and diminishes brain damage evaluated by 3 -Tesla magnetic resonance image after transient cerebral ischemia and reperfusion in rats. Brain Res. 2016 Sep;1646:384-92.

61 Zhan R, Zhao M, Zhou T, Chen Y, Yu W, Zhao L, et al. Dapsone protects brain microvascular integrity from high-fat diet induced LDL oxidation. Cell Death Dis. 2018 Jun;9(6):683.

62 Lee YI, Kang H, Ha YW, Chang KY, Cho SC, Song SO, et al. Diaminodiphenyl sulfone-induced parkin ameliorates age-dependent dopaminergic neuronal loss. Neurobiol Aging. 2016 May;41:1-10.

63 Allen SP, Seehra RS, Heath PR, Hall BP, Bates J, Garwood CJ, et al. Transcriptomic analysis of human astrocytes in vitro reveals hypoxiainduced mitochondrial dysfunction, modulation of metabolism, and dysregulation of the immune response. Int J Mol Sci. 2020 Oct;21(21):8028.

64 Sheibani M, Nezamoleslami S, Faghir-Ghanesefat H, Emami AH, Dehpour AR. Cardioprotective effects of dapsone against doxorubicin-induced cardiotoxicity in rats. Cancer Chemother Pharmacol. 2020 Mar;85(3):56371.
The Neuroinflammasome in $\mathrm{AD}$ and Cerebral Stroke
Dement Geriatr Cogn Disord Extra 2021;11:159-167 DOI: $10.1159 / 000516074$ 